\title{
Preventing falls in hospitalized elderly: design and validation of a team intervention*
}

\author{
A prevenção das quedas em idosos hospitalizados: elaboração e validação de uma intervenção \\ em equipe \\ La prevención de las caídas en ancianos hospitalizados: diseño y validación de una intervención \\ en equipo
}

How to cite this article:

Cunha LFC, Baixinho CL, Henriques MA. Preventing falls in hospitalized elderly: design and validation of a team intervention. Rev Esc Enferm USP. 2019;53:e3479. DOI: http://dx.doi.org/10.1590/S1980-220X2018031803479

(D) Luís Filipe Correia da Cunha ${ }^{1}$

(D) Cristina Lavareda Baixinho ${ }^{2}$

(D) Maria Adriana Henriques ${ }^{2}$

* Autor convidado WCQR, 2018.

${ }^{1}$ Center Hospital Lisbon

Central, Lisbon, Portugal.

${ }^{2}$ Nursing School of Lisbon, Nursing Research and Development Unit, Center

for Innovative Care and Health Technology - CiTheCare, Lisbon, Portugal.

\begin{abstract}
Objective: The objective of the present study was the design and validation, by a panel of experts, of a team intervention to manage the risk of falls in the hospitalized elderly. Method: The method used was a quanti-qualitative approach, using the Delphi method. The study was developed in two phases: in the first, five researchers designed the intervention; in the second, 13 professionals validated it. Results: The analysis of the content of the intervention designed by the participants in the first phase of the study allowed assignment of the indicators to the following previously defined categories: team formation; communication; leadership; monitoring; and mutual support. After two rounds, all the indicators obtained a consensus higher than $80 \%$. Conclusion: The present study allowed validation of a team intervention by a panel of experts, so that teams can manage the risk of falls in hospitalized elderly. The reliability test results ensure that the intervention can be used safely in clinics and for research.
\end{abstract}

\section{DESCRIPTORS}

Accidental Falls; Aged; Risk Management; Patient Care Team; Patient Safety. 


\section{INTRODUCTION}

Falls are a focus of attention in health, and they assume increasing importance in the aging population. They are considered to be an emerging problem whose resolution is of some urgency, due to the negative impact of falls on the functionality and quality of life in people over 65 years old ${ }^{(1-3)}$.

"Falls are the most frequently reported incidents in inpatient units for the elderly. Each year, somewhere between 700,000 and 1,000,000 people in the United States fall in hospitals. The rate of falls ranges from 1.7 to 25 falls per 1,000 patient days"(2).

Injuries resulting from falls are the main causes of hospitalization of the elderly and have a significant impact on their pain and suffering, as well as loss of their independence, constituting an important source of morbidity and mortality ${ }^{(1)}$. In addition, hospitalized elderly patients have a higher risk of falling, and $30 \%$ to $51 \%$ of falls in hospitals result in some type of injury ${ }^{(2)}$.

Interventions for prevention of falls must be individualized and multidimensional, involving caregivers, the environment, and the elderly. This implies that, beyond biomedical understanding, there is a more comprehensive understanding of falls that encompasses the psychological impact, emotions, and actions associated with falls and their necessary prevention ${ }^{(3)}$.

There is good evidence that falls can be prevented ${ }^{(1-2)}$. However, some authors consider that despite the enormous impact of falls on the elderly, there is still little evidence about the effectiveness of preventive interventions ${ }^{(4-5)}$. For this reason, some authors maintain that the challenge for health institutions is to implement effective fall prevention strategies that respond to the specifics and needs of each elderly person, based on programs implemented within multidisciplinary teams ${ }^{(5)}$. Regardless of how competent they are, professionals working alone cannot prevent all falls ${ }^{(2)}$. Fall prevention is a major challenge that requires the active engagement of multiple disciplines and teams involved in caring for patients ${ }^{(2)}$.

A study of the practices and behaviors of teams in the prevention of falls in institutionalized elderly people found that information about risk factors and team discussion of preventive measures is not always utilized, which may allow different members of teams to value different measures, compromising continuity of care and individualization of measures in response to the assessed risk ${ }^{(5)}$.

Another study aimed to evaluate the effectiveness of a crash prevention curriculum based on TeamSTEPPS ${ }^{\circledR}$. The results showed that team training and improved communication among team members about the risk of patient falls were effective in reducing the prevalence of $\mathrm{falls}^{\left({ }^{(6)}\right.}$. In and of itself, this justifies investment in teams, because they play a fundamental role in the implementation of best practices ${ }^{(7)}$ and in the translation of knowledge of the best evidence into clinical praxis.

In view of the above, some researchers recommend team intervention using TeamSTEPPS ${ }^{\circledR(6,8)}$. In other contexts, this program has reduced the likelihood of occurrence of incidents and injuries, and is assumed to make an important clinical contribution to the prevention of falls ${ }^{(8)}$, since prevention requires coordination, an organizational culture, and operational practices that promote teamwork and communication, as well as individual expertise ${ }^{(2)}$.

The structure of the program optimizes team performance throughout the healthcare delivery system and consists of 5 components: 1) Team structure, which must promote effectively team work to ensure patient safety; 2) Communication, based on a structured process whereby information is exchanged clearly and accurately among team members; 3) Leadership, which involves the ability to maximize the activities of team members, ensuring that team actions are understood, changes in information are shared, and team members have the necessary resources, 4) Monitoring, based on a process of active assessment of situational elements to obtain information and support team functioning; and 5) Mutual Support, based on the ability to anticipate and support the needs of team members through accurate knowledge of their responsibilities and workloads ${ }^{(8)}$.

A review of the literature showed that international guidelines and different studies recommend team interventions as a way to prevent falls in hospitalized elderly. However, evidence on the effectiveness of this approach is scarce, considering that studies have mostly focused on biomedical interventions ${ }^{(5)}$, whereas guidelines for team interventions focus on training regarding risk factors and preventive measures. For this reason, the authors of the present study considered it pertinent to design an intervention for hospital teams in the care of the elderly.

The objective of the present study comprises the design and validation, by a panel of experts, of a team intervention to manage the risk of falls in hospitalized elderly.

\section{METHOD}

\section{TYPE OF STUDY}

This study utilized a quanti-qualitative approach, and took place in the second half of 2017.

The research question was "What interventions by multidisciplinary teams can prevent the occurrence of falls in hospitalized elderly?" In order to achieve the study objectives, the Delphi method was used, which allows consensus among a panel of experts. This method is considered useful when evidence in an area is limited or contradictory, or when questions are largely unexplored or difficult to define ${ }^{(9-10)}$. Some authors argue that it is a particularly good research method for obtaining consensus among a group of individuals who have experience in a specific area ${ }^{(10-11)}$.

"Although commonly perceived as a quantitative method because of its focus on statistical consensus, the present study adopted a modified and open-ended Delphi method in order to facilitate a qualitative understanding of participants' experiences"(9). "A significant amount of literature has described the procedures involved in doing research using the Delphi method. However, less attention has been given 
to the specifically qualitative techniques in the process particularly coding"(9).

The research protocol of the present study was organized into the following steps: consultation with the researchers for the design of the intervention; content analysis of the interviews with the researchers; selection of experts with knowledge on the study area; information of participants; data analysis; and interpretation and presentation of the results $^{(9,11)}$.

One of the advantages of the method is that it enables participants to respond individually, promoting "dialogue" between experts from various geographical locations, preserving the anonymity and confidentiality of data. This is useful in mitigating the effects of power relations and can prevent domination of the group's opinion by one of the panel members ${ }^{(9)}$.

\section{Population}

For the intervention design, five researchers were selected who had published studies in the area of risk and/or prevention of falls in the elderly population. The researchers were contacted individually to request their collaboration and explain the study objectives. The purpose of consultation with these participants was to develop the design of the team intervention, based on the results of their investigations. The participants were interviewed individually.

For the validation of the designed intervention, the authors chose 13 professionals with more than five years of professional activity who were working in hospitals in the Lisbon area and Tagus Valley, and who had responsibilities in work groups on falls or safety and quality departments. The choice of two groups of heterogeneous participants (researchers and clinic professionals) was intentional, in order to ensure the validity of the results, since multidisciplinarity allows obtaining more valid predictive consensus ${ }^{(10)}$.

Both groups were individually contacted by one of the authors to report on the study objectives and request commitment to participate ${ }^{(9)}$ in the different rounds, indicate the time required, and inform them as to what would be done with the information ${ }^{(11)}$.

There was no contact between the two groups and the panel experts. Anonymity allows participants to discuss and assess issues more openly ${ }^{(9)}$.

\section{Data collection}

The Delphi method facilitates confidentiality and inclusivity. The rounds occurred online, rather than face-to-face, and the comments of the individual participants remained confidential, while maintaining a "virtual" dialogue on the aggregate findings ${ }^{(9)}$.

In order to enrich the dialogue in each category, a space was set up, in which participants could suggest the introduction and/or reformulation of indicators. The first round was carried out only with the researchers to obtain their contributions to the design of the intervention and for the definition of indicators by the categories defined a priori (team formation, communication, leadership, monitoring, and mutual support).

The questionnaire was created and sent using Google Drive ${ }^{\circledR}$. The experts were asked to comment on the indicators by giving them the following scores: $(-2)$ nothing relevant; (-1) little relevant; (0) I have no opinion; (1) relevant; and (2) very relevant.

Some authors suggest that $80 \%$ consensus should be the goal. Others suggest that percentages should not be used, but that the process should stop when data stability occurs ${ }^{(11)}$. For the present study, the objective was to obtain a consensus of $80 \%$ or more among the experts for each of the indicators under evaluation. After the first round instruments were submitted, followed by the descriptive statistics of the propositions and analysis of the suggestions for change/reformulation of items. The level of consensus and the suggestions were integrated according to the theoretical framework used.

\section{DATA ANALYSIS AND PROCESSING}

The answers to the proposed questions were subjected to content analysis, in order to decide which indicators to put in each of the previously defined categories. Content analysis was used to describe and interpret the content of the semi-structured interview responses by the experts. The analysis protocol included information preparation; transformation of the content into units; categorization; and description and interpretation.

For intervention validation, it was pre-defined that the indicators that did not obtain $80 \%$ consensus would be reformulated and re-sent in the next round ${ }^{(11)}$. SPSS version 13 was used for analysis and feedback was provided to the participants.

Content validation was done through application of the content validity index to each of the items (CVII) and the entire protocol (CVI). Interrater agreement (IRA) was used to evaluate inter-evaluator reliability or concordance ${ }^{(10)}$.

After the first round, the suggestions and reworked items were aggregated and returned to the participants, which allowed them to provide feedback on the findings.

Data from the first round were analyzed and returned to the panel within one month to avoid time lapses and declining participation ${ }^{(9)}$. The use of these measures made it possible to determine, by means of an iterative process, the extent of the agreement between the participants.

\section{ETHICAL ASPECTS}

The different institutions involved in the research provided authorization for the present study through a partnership protocol and by the ethical committee (Proc. 492/2017/n. ${ }^{\circ} 406$ ).

Regarding ethical aspects, the participants were first contacted to request their participation in the panel of experts. After obtaining a positive response, the participation link was sent, along with a guarantee that the answers would be anonymous. Recording the entry of the responses on Google Drive ${ }^{\circledR}$ did not allow the identification of email addresses or names of the responding experts. 


\section{RESULTS}

The five researchers who collaborated in the design of the team intervention had $\mathrm{PhDs}$ and had carried out research in the area of falls in the elderly population. The analysis of the answers of these experts allowed the definitions of the indicators to be placed in previously defined categories (team formation, communication, leadership, monitoring, and mutual support) (Table 1).

The 13 experts who validated the intervention using the Delphi technique had an average age of 37.4 years and had worked on average for 15.3 years. Regarding educational level, $46.1 \%$ had a degree, $38.5 \%$ had a master's degree, and 15.4\% had a PhD.

Table 1 shows the categories defined a priori and the indicators, which were subject to evaluation by the panel of experts, as well as the level of agreement between the experts obtained in the first round.

It should be noted that in order to obtain the levels of agreement, the answers given scores of (1) relevant and (2) very relevant were considered valid.

Table 1 - Expert agreement (first round of evaluation) in relation to the indicators of the team intervention - Lisbon, Portugal, 2018.

\begin{tabular}{|c|c|c|c|c|}
\hline & Dimensions of the team intervention to manage the risk of falls in the hospitalized elderly & CVII* & IRA** & $\mathrm{CVI} * * *$ \\
\hline \multicolumn{5}{|c|}{ Team Formation } \\
\hline 1 & Risk assessment & 1 & \multirow{11}{*}{.84} & \\
\hline 3 & Familiarization of the user with the environment & .84 & & \\
\hline 4 & Keeping the call light in range & .92 & & \\
\hline 5 & Keeping personal belongings within reach & .84 & & \\
\hline 6 & Placement of bed in a low position when the user is lying down & .84 & & \\
\hline 7 & Keeping the bed locked & 1 & & \\
\hline 8 & Supply of non-slip footwear & .84 & & \\
\hline 9 & Use of night lights or supplementary lighting & .92 & & \\
\hline 10 & Maintenance of clean and dry floor surfaces & 1 & & \\
\hline 11 & Provision of relevant information and support to the elderly and family/caregivers & .84 & & \\
\hline 13 & Strategies for elderly involvement in any multifactorial interventions & .69 & & \\
\hline \multicolumn{5}{|c|}{ Communication } \\
\hline 14 & Meet periodically with the team & 1 & \multirow{5}{*}{1} & \\
\hline 15 & Post monthly information on the wardrobe on the prevalence of falls & .92 & & \\
\hline 16 & $\begin{array}{l}\text { At the time of shift changes, ask colleagues for information on the risk of falls in the elderly } \\
\text { hospitalized in the last } 24 \text { hours }\end{array}$ & .84 & & \\
\hline 17 & Encourage the team to discuss the preventive measures implemented and their effectiveness & 1 & & \\
\hline 18 & $\begin{array}{l}\text { Create a fall event log to record the date, time, place of occurrence, mechanism of the fall, } \\
\text { activity that was being performed, resulting injuries, and if the fall was witnessed }\end{array}$ & 1 & & \\
\hline \multicolumn{3}{|c|}{ Leadership } & \multirow{6}{*}{1} & .92 \\
\hline 19 & Promote discussion among the multidisciplinary team about how to do fall risk assessment & 1 & & \\
\hline 20 & Encourage the team to implement individualized preventive measures for falls & 1 & & \\
\hline 21 & Promote increased space security by monitoring equipment and materials & .92 & & \\
\hline 22 & Promote periodic training actions on the subject & 1 & & \\
\hline 24 & Develop team confidence about communicating protracted fall episodes & 1 & & \\
\hline \multicolumn{4}{|c|}{ Monitoring } & \\
\hline 25 & Apply the Morse Fall Scale to all elderly patients & 1 & \multirow{8}{*}{1} & \\
\hline 26 & Assessment with the TUG test in the elderly with a high risk of falls & .84 & & \\
\hline 27 & Analysis of records on implemented preventive measures & 1 & & \\
\hline 28 & Analysis of the oral information transmitted during shift changes & .84 & & \\
\hline 29 & $\begin{array}{l}\text { Verification of information in the discharge/transfer chart on the evaluation of the risk of } \\
\text { falls at the time of discharge }\end{array}$ & 1 & & \\
\hline 30 & $\begin{array}{c}\text { Verification of information in the discharge/discharge chart on preventive measures for falls } \\
\text { during hospitalization }\end{array}$ & .92 & & \\
\hline 31 & $\begin{array}{c}\text { Verification of information in the discharge/discharge chart on the occurrence of falls } \\
\text { during hospitalization }\end{array}$ & 1 & & \\
\hline 32 & Verification of education information & .92 & & \\
\hline \multicolumn{5}{|c|}{ Mutual support } \\
\hline 33 & Regular meetings & 1 & \multirow{3}{*}{1} & \\
\hline 34 & Positive reinforcement when implementing security measures & 1 & & \\
\hline 35 & Not assigning blame & 1 & & \\
\hline
\end{tabular}

Legend: *content validity index, applied to the indicator; ${ }^{* *}$ Interrater agreement, applied to the dimensions; ${ }^{* * *}$ content validity index for intervention. 
Among the 13 indicators (I) in the team training category, the clinical experts considered that "Determination of unsafe behaviors" (I2) and the "Strategies for elderly involvement in any multifactoral interventions" (I13) could be addressed in team education (P12). However, "Confused elderly people with dementia and altered states of consciousness cannot objectively assess what is safe behavior, and they cannot be involved in prevention"(P12), so the experts suggested changing these two indicators to "importance of reinforcing safe behavior of the elderly and/or the team"(P3) as a subject to be worked into the interdisciplinary training. They suggested the introduction of "Safe use of information on risk and/or prevention information" in training.

In the communication category for indicator I18, two experts (P2, P7) considered that the recording of fall episodes should be based on the WHO Conceptual Framework for the International Classification of Patient Safety. This item was not submitted to the second round since it obtained $100 \%$ consensus in the first round.

Regarding Leadership and Monitoring beyond consensus, there were no suggestions for changes or inclusion of new indicators.

In the last category, Mutual Support, one participant (P9) suggested the addition of the indicator "Support in case of incidents resulting in serious injury or death".

Table 2 shows the indicators under evaluation in the second round and the level of agreement obtained among the experts.

Table 2 - Expert agreement on the indicators evaluated in the second round - Lisbon, Portugal, 2018.

\begin{tabular}{ccc}
\hline & Indicator & CVII \\
\hline 2 & $\begin{array}{c}\text { Importance of reinforcing the safe behavior of the } \\
\text { elderly and/or the team }\end{array}$ & .92 \\
13 & $\begin{array}{c}\text { Safe use of information on risk and/or prevention } \\
\text { information }\end{array}$ & .84 \\
36 & $\begin{array}{c}\text { Support in case of incidents resulting in serious injury } \\
\text { or death }\end{array}$ & 1 \\
\hline
\end{tabular}

After the second round and the evaluation of the three indicators, the entire validated intervention had 36 indicators. The first category had an IRA $=0.89$, and the CVI of the intervention increased from 0.92 to 0.94 .

\section{DISCUSSION}

The risk of falls in hospitalized patients is complex, and is related to intrinsic and extrinsic factors, comorbidities, and types of hospitalization ${ }^{(12)}$. The multifactorial nature and complexity of the relationship among fall risk factors make it difficult to control this problem. The prevention of falls implies multiprofessional teamwork, with interventions directed by teams that play a crucial role in the implementation of best practices, from risk assessment to implementation of preventive measures and communication of fall episodes ${ }^{(5)}$.
A review of the literature showed that there have been recommendations for team interventions and studies that have focused on the development of communication processes and their impact on decreases in prevalence, risk and associated injuries ${ }^{(5-6,8)}$. However, there has been no work focused on structured team interventions in order to develop skills in managing the fall risk of the elderly population. This review also made it possible to organize the intervention into five categories that the authors consider central to team interventions: team formation; communication; leadership; monitoring; and mutual support ${ }^{(5-6,8)}$.

Given the above, the validation of an intervention for multiprofessional teams can provide support for clinical and research efforts in this area. Despite criticism by some authors regarding the method used and the level of evidence of consensus by experts, the authors are pleased to advocate the use of validated instruments as a pillar in the prevention of falls ${ }^{(13)}$, not only for risk assessment, but also for intervention.

The first category - team training - has 13 indicators with an IRA $=0.89$, grouping the contents of the specific training for team intervention in the control of risk factors. In view of the multiplicity of fall risk factors, training that the team should provide to hospitalized elderly patients and their families was excluded. It is important that the team understand that there are risk factors that need to be controlled only by the team, and that others involve shared responsibility with the hospitalized person. It should be noted that team practices of communicating risk factors are low, which means that they are not discussed in most cases, which may indicate underestimation of fall risk ${ }^{(5)}$.

The training of professionals is vital to the success of fall prevention programs in increasing quality of life and reducing costs ${ }^{(14)}$. Some authors consider staff training to be a crucial element in prevention programs, since it increases adherence to reporting fall episodes and keeping more complete records ${ }^{(15)}$.

The second category, referring to the five communication indicators, obtained an IRA $=1$. Improving team communication by sharing accurate information about the behaviors of the elderly, along with health status, medications, and other risk factors, may contribute to a $12 \%$ decrease in fall episodes ${ }^{(16)}$.

A study of a multi-intervention protocol involving multiprofessional collaboration demonstrated that combined fall prevention interventions, including team training to improve interdisciplinary fall risk communication, were effective in reducing the number of fall episodes ${ }^{(17)}$. Another study aimed to evaluate the effectiveness of a crash prevention curriculum based on TeamSTEPPS. The results showed that team training and improved communication among team members about the risk of patient falls were effective in reducing the prevalence of falls ${ }^{(6)}$.

The creation of a fall event $\log$ (I18) is very useful for the control of fear of falling, which is common among the elderly who have already suffered falls and who end up 
losing confidence in the performance of daily and instrumental activities ${ }^{(18)}$.

The six indicators in the leadership category achieved a consensus greater than $92 \%$ in the first round. The high prevalence of falls justifies coordination among multiprofessional health teams at all levels of care, aiming at detecting the elderly who are at risk of falling or have a previous history of falls ${ }^{(19)}$. However, in order to reach this major goal, effective team leadership is required, and the development of a safety culture is essential ${ }^{(17)}$.

Training, coupled with supervision and leadership, and linked to evidence-based policies and procedures, has a positive impact ${ }^{(20)}$ on fall control.

Some authors have argued that a safety culture is the first step for fall prevention programs to be integrated into organizations, and note that the development of a safety culture requires changes in the attitudes, beliefs, and behaviors of professionals and management ${ }^{(21)}$. This process requires strong leadership, effective communication, development of new policies, and training of multiprofessional teams ${ }^{(22)}$. The individuals responsible for institutions or prevention programs should be proactive in promoting and introducing international guidelines for care in residential units for the elderly, especially with regard to preventive measures ${ }^{(20)}$.

The fourth category - monitoring - has eight indicators, which obtained more than $80 \%$ consensus in the first round. Systematic monitoring of safety and adverse events, including falls, is essential to reducing fall prevalence ${ }^{(20)}$. Professionals have a responsibility to reduce the incidence of these events. The care provided and their efforts in this regard must ensure the safety and well-being of the elderly ${ }^{(20)}$. The safety of the environment must be guaranteed for all patients, regardless of risk, since hospitals represent an unknown and unfamiliar environment, and are more critical for the elderly ${ }^{(23)}$. Policies and (legislation) must allow the detection of poor practices and deal with situations where safety may be compromised ${ }^{(20)}$.
The fifth and last category, mutual report, relates to the three indicators suggested by the participants in the first phase of the study, which were included in the first round and unanimously evaluated as very relevant. One of the experts suggested introducing another indicator: "Support in case of incidents resulting in serious injury or death". This team intervention is very pertinent, given that in the European Union there are close to 40,000 deaths of elderly people. Since the proportion of elderly people is increasing, aging will have an immediate effect on the impact of injuries in this age group ${ }^{(24)}$. Concomitantly, professionals experience feelings of guilt about fall ${ }^{(5)}$.

The present study has limitations that are inherent to the method and the sample type, with intentional choice of the participants in the two phases of the investigation. It is also emphasized that the designed intervention was based on the self-perceptions and clinical knowledge of the experts, and the responses may have been influenced by what is considered socially desirable. Also, sending the document in an electronic format increased the likelihood of bias in the experts' answers, due to the possibility that the answers were influenced by other sources.

\section{CONCLUSION}

The present study allowed validation of a team intervention by a panel of experts, allowing teams to manage the risk of falls in hospitalized elderly. The intervention is organized into five domains (categories): team formation; communication; leadership; monitoring; and mutual support.

Based on the analysis of the contributions of five researchers, whose responses were subject to content analysis, the intervention was designed and validated by 13 experts. The values obtained in the reliability test $(>0.8)$ show that the intervention can be used in clinical and research settings to achieve the desired goals. The next step is the implementation of this intervention by multidisciplinary teams to evaluate its effectiveness in reducing the prevalence of falls in the hospitalized elderly population.

\section{RESUMO}

Objetivo: O objetivo do presente estudo foi a elaboração e validação, por um painel de especialistas, de intervenção em equipe para lidar com o risco de quedas nos idosos hospitalizados. Método: O método usado foi uma abordagem quanti-qualitativa, utilizando o método Delphi. O estudo foi desenvolvido em duas fases: na primeira, cinco pesquisadores elaboraram a intervenção; na segunda, 13 profissionais a validaram. Resultados: A análise do conteúdo da intervenção elaborada pelos participantes na primeira fase do estudo permitiu a avaliação dos indicadores para as seguintes categorias definidas previamente: formação de equipe; comunicação; liderança; monitoramento; e suporte mútuo. Após duas rodadas, todos os indicadores obtiveram um consenso superior a $80 \%$. Conclusão: O presente estudo permitiu a validação de uma intervenção em equipe por um painel de especialistas, para que as equipes possam lidar com o risco de quedas nos idosos hospitalizados. Os resultados do teste de confiabilidade garantem que a intervenção pode ser usada de forma segura na clínica e para pesquisa.

\section{DESCRITORES}

Acidentes por Quedas; Idoso; Gestão de Riscos; Equipe de Assistência ao Paciente; Segurança do Paciente.

\section{RESUMEN}

Objetivo: El objetivo del presente estudio fue el diseño y la validación, por un panel de expertos, de intervención en equipo para manejar el riesgo de caídas en los ancianos hospitalizados. Método: El método empleado fue un abordaje cuanti-cualitativo, utilizándose el método Delphi. El estudio fue desarrollado en dos fases: en la primera, cinco investigadores diseñaron la intervención; en la segunda, 13 profesionales la validaron. Resultados: El análisis del contenido de la intervención diseñada por los participantes en la primera fase del estudio permitió la evaluación de los indicadores para las siguientes categorías: formación de equipo; comunicación; liderazgo; monitoreo; y soporte mutuo. Luego de dos ruedas, todos los indicadores lograron un consenso superior al 80\%. Conclusión: El presente estudio permitió la validación de una intervención en equipo por un panel de expertos, a fin de que los equipos puedan manejar el riesgo 
de caídas en los ancianos hospitalizados. Los resultados de la prueba de confiabilidad aseguran que la intervención puede emplearse de modo seguro en la clínica y para investigación.

\section{DESCRIPTORES}

Accidentes por Caídas; Anciano; Gestión de Riesgos; Grupo de Atención al Paciente; Seguridad del Paciente.

\section{REFERENCES}

1. Burland B, Martens P, Brownell M, Doupe M, Fuchs D. The evaluation of a fall management program in a nursing home population. Gerontologist. 2013;53(5):828-38. DOI: 10.1093/geront/gns197

2. Agency for Healthecare Research and Quality (AHRQ). Preventing falls in hospitals: a toolkit for improving quality of care. Washington: AHRQ; 2013.

3. Baixinho $\mathrm{CL}$, Dixe MA. Construction and validation of the scale of practices and behaviors of institutionalized elderly to prevent falls. Univ J Public Health. 2016;4(3):139-43. DOI: 10.13189/ujph.2016.040303

4. Damián J, Pastor-Barriuso R, Valderrama-Gama E, Pedro-Cuesta J. Factors associated with falls among older adults living in institutions. BMC Geriatr. 2013;13:6. DOI: 10.1186/1471-2318-13-6

5. Baixinho CL, Dixe MA. Team practices in fall prevention in institutionalized elderly people: scale design and validation. Texto Contexto Enferm. 2017;26(3):e2310016. DOI: https://dx.doi.org/10.1590/0104-07072017002310016

6. Spiva L, Robertson B, Delk ML, Patrick S, Kimrey MM, Green B, et al. Effectiveness of team training on fall prevention. J Nurs Care Qual. 2014;29(2):164-73. DOI: 10.1097/NCQ.0b013e3182a98247

7. Fixsen D, Scott V, Blasé K, Naoom S, Magar L. When evidence is not enough: the challenge of implementing fall prevention strategies. J Safety Res. 2011;42(6):419-22. DOI: 10.1016/j.jsr.2011.10.002

8. Godlock G, Christiansen M, Feider L. Implementation of an evidence-based patient safety team to prevent falls in inpatient medical units. Medsurg Nurs. 2016;25(1):17-23. DOI: PMID 27044124

9. Fletcher AJ, Marchildon GP. Using the Delphi method for qualitative, participatory action research in health leadership. Int J Qual Methods. 2014;13(1):1-18. DOI: https://doi.org/10.1177/160940691401300101

10. Waltz C, Strickland O, Lenz E. Measurement in nursing and health research. $5^{\text {th }}$ ed. New York: Springer; 2016.

11. Grisham T. The Delphi technique: a method for testing complex and multifaceted topics. Int J Manag Projects Business. 2008;2(1):112-30. DOI: $10.1108 / 17538370910930545$

12. Bittencourt VLL, Graube SL, Stumm EMF, Battisti IDE, Loro MM, Winkelmann ER. Factors associated with the risk of falls in hospitalized adult patients. Rev Esc Enferm USP. 2017;51:e03237. DOI: http://dx.doi.org/10.1590/S1980-220X2016037403237

13. Ruan W, Yao L, Sheng QZ, Falkner N, Li X, Gu T. TagFall: towards unobstructive fine-grained fall detection based on uhf passive RFID tags. EAI Endor Transact Internet Things. 2015;15(2):e4. DOI 10.4108/eai.22-7-2015.2260072

14. Teresi JA, Ramirez M, Remler D, Ellis J, Boratgis G, Silver S, et al. Comparative effectiveness of implementing evidenced-based education and best practices in nursing homes: effects on falls, quality-of-life and societal costs. Int J Nurs Stud. 2013;50(4):448-63. DOI: 10.1016/j. ijnurstu.2011.07.003

15. Nitz J, Cyarto E, Andrews S, Fearn M, Fu S, Haines T, et al. Outcomes from the implementation of a facility-specific evidence-based falls prevention intervention program in residential aged care. Geriatr Nurs. 2012;33(1):41-50. DOI: 10.1016/j.gerinurse.2011.11.002

16. Colon-Emeric CS, McConnell E, Pinheiro SO, Corazzini K, Porter K, Earp KM, et al. CONNECT for better fall prevention in nursing homes: results from a pilot intervention study. J Am Geriatr Soc. 2013;61(12):2150-9. DOI:10.1111/jgs.12550. doi: 10.1111/jgs.12550

17. Jackson KM. Improving nursing home falls management program by enhancing standard of care with collaborative care multi-interventional protocol focused on fall prevention. J Nurs Educ Pract. 2016;6(6):84-96. DOI: https://doi.org/10.5430/jnep.v6n6p84

18. Marques-Vieira CMA, Sousa LMM, Severino S, Sousa L, Caldeira S. Cross-cultural validation of the Falls Efficacy Scale International in Elderly: systematic literature review. J Clin Gerontol Geriatr. 2016;7(3):72-6. DOI: http://dx.doi.org/10.1016/j.jcgg.2015.12.002

19. Nascimento JS, Tavares DMS. Prevalence and factors associated with falls in the elderly. Texto Contexto Enferm. 2016;25(2):e0360015. DOI: http://dx.doi.org/10.1590/0104-07072016000360015

20. Duffy A. The assessment and management of falls in residential care settings. Br J Nurs. 2013;22(5):259-63. DOI: https://doi.org/10.12968/ bjon.2013.22.5.259

21. Taylor JA, Parmelee P, Brown H, Ouslander JG. The falls management program: a quality improvement initiative for nursing facilities. Washington: Agency for Healthcare Research and Quality; 2005.

22. Taylor JA, Parmelee P, Brown H, Strothers HS, Capezuti E, Ouslander JG. A model quality improvement program for the management of falls in nursing homes. J Am Med Dir Assoc. 2007;8(3 Suppl):26-36. DOI: 10.1016/j.jamda.2006.11.005

23. Luzia MF, Cassola TP, Suzuki LM, Dias VLM, Pinho LB, Lucena AF. Incidence of falls and preventive actions in a University Hospital. Rev Esc Enferm USP. 2018;52:e03308. DOI: http://dx.doi.org/10.1590/S1980-220X2017024203308

24. Portugal. Ministério da Saúde. Direcção-Geral da Saúde. Programa Nacional de Prevenção de Acidentes: 2010-2016. Lisboa: DirecçãoGeral de Saúde; 2010. 